\title{
РОЛЬ БАНКА РОССИИ В СОВЕРШЕНСТВОВАНИИ РОССИЙСКОЙ БАНКОВСКОЙ СИСТЕМЫ
}

\begin{abstract}
АНнотАция. В настоящее время крайне актуальным выступает вопрос о результативности применяемых методов регулирования Банка России. Анализ современной экономической научной литературы свидетельствует об отсутствии единого мнения по результатам применяемой Банком России стратегии развития. С одной стороны, официальная позиция Банка России соответствует заявленным целям по снижению инфляции и оздоровлению банковского сектора. С другой стороны Центральный банк подвергается критике о не соответствующим целям, которые противоречат развитию экономики России. Статья посвящена развитию Банком России банковской системы России, на примере Федеральной Резервной Системы США рассмотрены функции Центрального Банка России, с наибольшим вниманием выделяются функции развития экономики, проведен мониторинг отзывов лицензий у коммерческих банков с целью показать направленность регулятора на стабилизацию всего банковского сектора и выявлены причины замедленного развития банковской системы. кЛЮчЕВЫЕ слОВА. Банк России; банковская система; коммерческие банки; лицензирование.
\end{abstract}

ИНФОРМАЦИЯ О СТАТЬЕ. Дата поступления 28 апреля 2017 г.; дата принятия к печати 18 мая 2017 г.; дата онлайн-размещения 19 июня 2017 г.

M. G. Zhigas

Baikal State University, Irkutsk, Russian Federation

G. V. Chekurkov

Baikal State University, Irkutsk, Russian Federation

\section{ROLE OF RUSSIA'S CENTRAL BANK IN IMPROVING RUSSIAN BANKING SYSTEM}

ABSTRACT. Currently, of hot issue is the topic of effectiveness of the Bank of Russia's applied methods of regulation. An analysis of modern economic scientific literature testifies the lack of a common opinion of the results of the development strategy applied by the Bank of Russia. On the one hand, the official position of the Bank of Russia corresponds the declared targets in lowering the inflation and improvement of the banking sector. On the other hand, the Central Bank is criticized for the noncorresponding targets that contradict development of Russia's economy. The article is devoted to developing Russia's banking system by the Bank of Russia; using the example of the USA Federal System it considers the functions of Russia's Central Bank, identifying most carefully the functions of economic development; it carries out monitoring the revocation of licenses from commercial banks in order to show the regulator orientation for stabilizing the whole banking sector and determining the causes of retarded development of the banking system.

KEYWORDS. Bank of Russia; banking system; commercial banks; licensing.

ARTICLE INFO. Received April 28, 2017; accepted May 18, 2017; available online June 19, 2017.

(C) М. Г. Жигас, Г. В. Чекурков, 2017

\section{Baikal Research Journal}


На современном этапе развития российской экономики, в условиях нестабильности и политической напряженности, ключевую роль играет эффективная деятельность как Центрального банка, так и всей банковской системы в целом, которая обеспечивает финансовыми ресурсами предприятия, организации и малый бизнес, составляющий основу любой развитой рыночной экономики.

Принципиально важным моментом выступает развитие регулирующих органов, с целью надзора и своевременного вмешательства в процессы, которые могут нанести существенный ущерб системе. Банк России, являясь ответственным органом, за разработку и реализацию денежно-кредитной политики, при помощи утвержденных инструментов и методов определяет условия функционирования целым секторам экономики.

В современном мире роль регулирующего органа банковской системы существенна, поскольку от его направляющих импульсов происходит прямонаправленное воздействие на экономическую активность. В мировой практике Центральные Банки несут ответственность не только за денежно-кредитную политику, но и своими действиями влияют на экономическую ситуацию, в целом, наглядным примером в данном случае служит Федеральная Резервная Система США (далее по тексту ФРС). Центральный Банк США (ФРС), при реализации монетарной политики, оказывает влияние не только на финансовые рынки, но и непосредственно на занятость населения и реальный сектор экономики. В главных документах банка (Federal Reserve Act и The Federal Reserve System purposes \& functions) установлены цели деятельности, диктующие условия при которых функционирует ФРС. Ключевым понятием данного закона является раскрытие целей монетарной политики: совет управляющих ФРС и Федерального комитета по открытым рынкам должен поддерживать долгосрочный рост денежных и кредитных агрегатов соразмерно с долгосрочным экономическим потенциалом для того чтобы увеличить производство, а также эффективно содействовать целям максимальной занятости, стабильных цен и умеренных долгосрочных процентных ставок ${ }^{1}$.

В России перед Центральным банком (ЦБ РФ) в соответствие с федеральным законом «О Центральном банке Российской Федерации (Банке России)» от 10 июля 2002 г. № 86-ФЗ установлены иные цели деятельности (табл. 1).

Действующие полномочия Банка России расширились в соответствии с принятием федерального закона «О внесении изменений в отдельные законодательные акты Российской Федерации в связи с передачей Центральному банку Российской Федерации полномочий по регулированию, контролю и надзору в сфере финансовых рынков» от 23 июля 2013 г. № 251-ФЗ. Банк России получил функции мегарегулятора по примеру таких же институтов в 161 стране мира ${ }^{2}$. Основная цель его создания заключается в одновременном обеспечении устойчивости финансового сектора как на макропруденциальном (минимизация системного риска финансового рынка), так и на микропруденциальном уровне (поддержание устойчивого финансового положения отдельных финансовых посредников для защиты интересов вкладчиков, кредиторов и инвесторов). В результате упразднения Федеральной службы по финансовым рынкам (далее по тексту ФСФР) Банк России стал обладать следующими функциями:

- разрабатывает и проводит политику развития и обеспечения стабильности функционирования финансового рынка Российской Федерации (во взаимодействии с Правительством РФ);

\footnotetext{
${ }^{1}$ Federal Reserve Act // Board of governors of the Federal Reserve System. URL: http://www.federalreserve.gov/aboutthefed/fract.htm.

${ }^{2}$ Мегарегулятор. URL:http://www.banki.ru/wikibank/megaregulyator/.
}

\section{Baikal Research Journal}


Сравнение целей и функиий Центральных банков США и России

\begin{tabular}{|l}
\hline \multicolumn{1}{|c|}{ ФРС } \\
\hline Проведение денежно-кредитной политики \\
страны путем влияния на денежно-кре- \\
дитные условия в экономике с целью \\
достижения максимальной занятости \\
населения, стабильных цен и умеренных \\
долгосрочных процентных ставок. \\
Контроль и регулирование банковских \\
учреждений для обеспечения безо- \\
пасности и надежности банковской и \\
финансовой системы страны и защиты \\
кредитных прав потребителей. \\
Поддержание стабильности финансо- \\
вой системы и сдерживание системного \\
риска, который может возникнуть на \\
финансовых рынках. \\
Предоставление финансовых услуг \\
депозитным учреждениям, правитель- \\
ству СШаА и иностранным официальным \\
учреждениям [1]
\end{tabular}
учреждениям [1]

\section{Выполнение функций Центрального}

Банка.

Регулирование баланса между интересами частных банков и государства.

Обеспечение надзора и регуляции банковских учреждений.

Защита прав потребителей банковских услуг.

Управление денежной эмиссией.

Обеспечение стабильности работы финансовой системы США.

Предоставление финансовых услуг для депозитариев (включая правительство

США и иностранные официальные учреждения).

Участие в системе международных платежей.

Участие в системе внутренних платежей.

Устранение проблем с ликвидностью

\section{Функиии}

Разработка и проведение единой государственной денежно-кредитной политики.

Во взаимодействии с Правительством Российской Федерации разрабатывает и проводит политику развития и обеспечения стабильности функционирования финансового рынка Российской Федерации.

Монопольно осуществляет эмиссию наличных денег и организует наличное денежное обращение.

Является кредитором последней инстанции для кредитных организаций, организует систему их рефинансирования. Устанавливает правила осуществления расчетов в Российской Федерации.

Осуществляет надзор и наблюдение в национальной платежной системе.

Устанавливает правила проведения банковских операций. Осуществляет обслуживание счетов бюджетов всех уровней бюджетной системы Российской Федерации, если иное не установлено федеральными законами, посредством проведения расчетов по поручению уполномоченных органов исполнительной власти и государственных внебюджетных фондов, на которые возлагаются организация исполнения и исполнение бюджетов.

Осуществляет эффективное управление золотовалютными резервами Банка России.

Принимает решение о государственной регистрации кредитных организаций, выдает кредитным организациям лицензии на осуществление банковских операций, приостанавливает их действие и отзывает их.

Принимает решения о государственной регистрации негосударственных пенсионных фондов.

Осуществляет надзор за деятельностью кредитных организаций и банковских групп.

Осуществляет регулирование, контроль и надзор за деятельностью некредитных финансовых организаций в соответствии с федеральными законами.

Осуществляет регистрацию выпусков эмиссионных ценных бумаг и проспектов ценных бумаг, регистрацию отчетов об итогах выпусков эмиссионных ценных бумаг.

Осуществляет контроль и надзор за соблюдением эмитентами требований законодательства Российской Федерации об акционерных обществах и ценных бумагах.

Осуществляет регулирование, контроль и надзор в сфере корпоративных отношений в акционерных обществах.

\section{Baikal Research Journal}


Окончание табл. 1

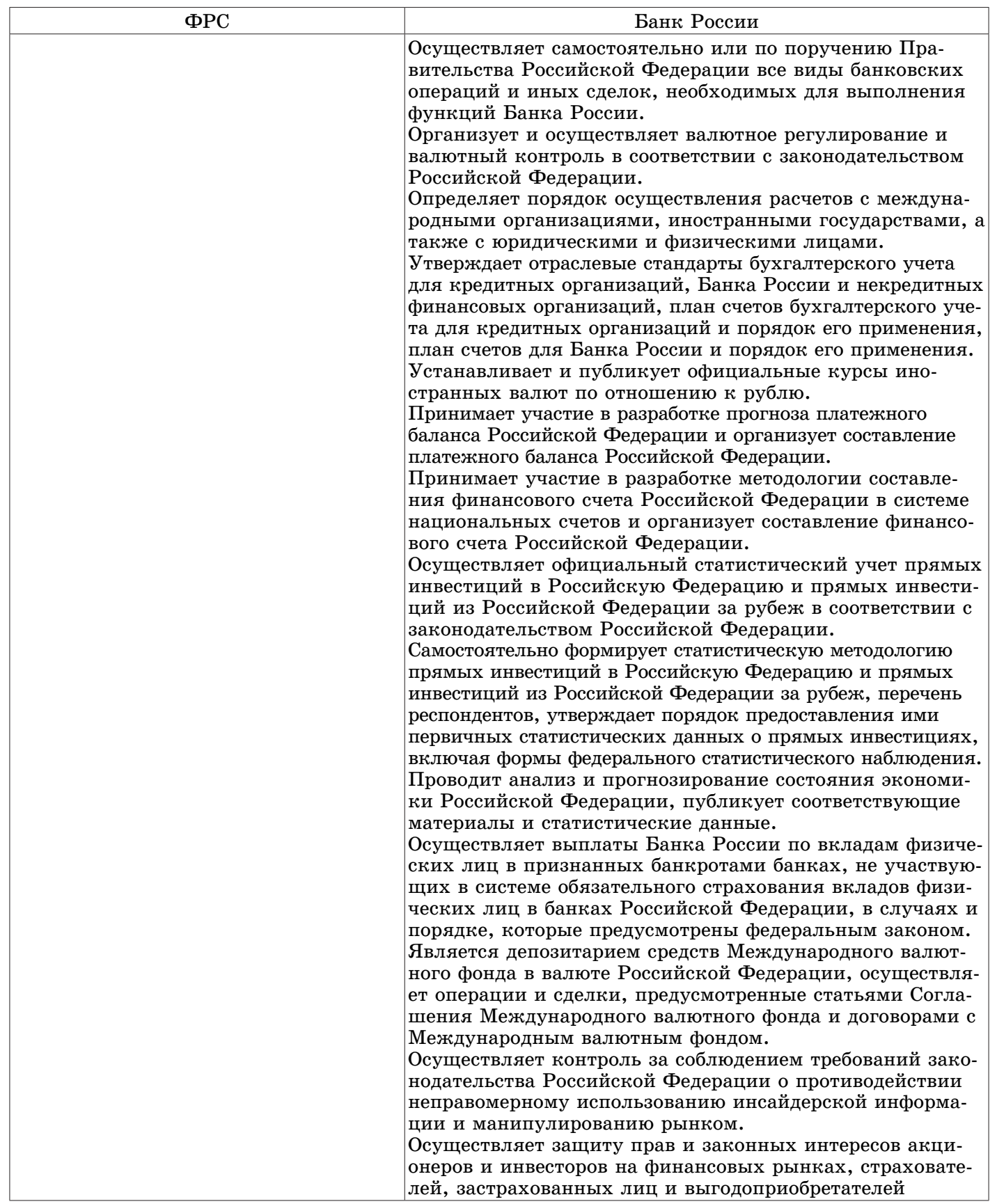

Составлено по данным: О Центральном банке Российской Федерации (Банке России) : федер. закон РФ от 10 июля 2002 г. № 86-ФЗ : (ред. от 4 нояб. 2014 г.) // СПС «КонсультантПлюс»; Federal Reserve Act. URL: http://www.federalreserve.gov/aboutthefed/fract.htm.

- осуществляет регулирование, контроль и надзор за деятельностью некредитных финансовых организаций (в том числе страховых, клиринговых, микрофинансовых организаций, НПФ, ПИФ и др.);

\section{Baikal Research Journal}


- осуществляет контроль и надзор за соблюдением эмитентами требований законодательства РФ об акционерных обществах и ценных бумагах;

- осуществляет регулирование, контроль и надзор в сфере корпоративных отношений в акционерных обществах;

- осуществляет защиту прав и законных интересов акционеров и инвесторов на финансовых рынках, страхователей, застрахованных лиц и выгодоприобретателей, а также застрахованных лиц по обязательному пенсионному страхованию, вкладчиков и участников негосударственного пенсионного обеспечения ${ }^{3}$.

Актуальность создания мегарегулятора обусловлена неразвитой национальной финансовой системой в России, регулирование которой находится развивающейся стадии. Недостаточно развитая национальная финансовая система, тормозит развитие экономики, что приводит ее к риску возникновения кризиса.

Результатом деятельности финансового мегарегулятора должно стать создание в России укрепление отечественного финансового рынка, раскрытие его потенциала благодаря более дифференцированному подходу к участникам рынка и более ясной, открытой системе регулирования и надзора

Банк России, являющийся регулятором, в том числе и страхового рынка, отвечает за защиту интересов потребителей. Доктор экономических наук, профессор М. Г. ЖЖигас в своей статье «развитие страховой защиты и финансово-экономические особенности страховой деятельности» поднимает проблематику развития страховой защиты, страховых отношений и особенно выделяет работу страховой организации в части ее деятельности с децентрализованными страховыми фондами [1]. Таким образом, развитие экономики не возможно без слаженной работы всех субъектов экономики, наделением Банком России функций мегарегулятора в настоящий момент вызывает неоднозначную реакцию в научном сообществе. Так Н. А. Звягинцева в своей статье «Реформирование системы государственного регулирования рынка ценных бумаг: путь к мегарегулятору» указывает на возможные проблемы, связанные с чрезмерным контролем, со стороны органов государственной власти и ставиться вопрос о невозможности признать деятельность органов государственного регулирования безусловно эффективной [2].

По нашему мнению, развитие экономики и как следствие влияние своих действий на субъекты экономики пока не входит в область компетенции ЦБ РФ, что влечет за собой дисбаланс. Например, ярким примером действий ЦБ РФ можно было наблюдать решение об изменение ключевой ставки в конце 2014 г. Тогда ЦБ РФ принял решение о поднятии значения ключевой ставки на 70 \% с 10,5 до $17 \%$ (рис. 1).

Данное изменение существенно ограничило доступ к краткосрочному кредитованию для коммерческих банков, с учетом санкций и отсутствия возможности фондирования из иностранных источников фактически привело к невозможности привлечения кредитными организациями ресурсов, вследствие чего вырос спрос на дорогой источник привлечения ресурсов - вклады. Произошло сжатие экономическую активность, что привело к снижению количества и объемов спекуляций на валютном рынке, которые способствовали снижению курса доллара США и росту инфляции, вследствие отсутствия заемной рублевой массы. Следует согласиться с мнением банковского и экономического сообщество о негативном влиянии на предпринимательскую активность в России - объем валового внутреннего продукта (ВВП) снизился на 3,7 \%. Схожие последствия наблюдались в 2009 г. когда падение ВВП составило 7,8 \% (рис. 2).

${ }^{3} \mathrm{O}$ внесении изменений в отдельные законодательные акты Российской Федерации в связи с передачей Центральному банку Российской Федерации полномочий по регулированию, контролю и надзору в сфере финансовых рынков : федер. закон РФ от 1 сент. 2013 г. № 251-ФЗ // СПС «КонсультантПлюс».

\section{Baikal Research Journal}

электронный научный журнал Байкальского государственного университета 


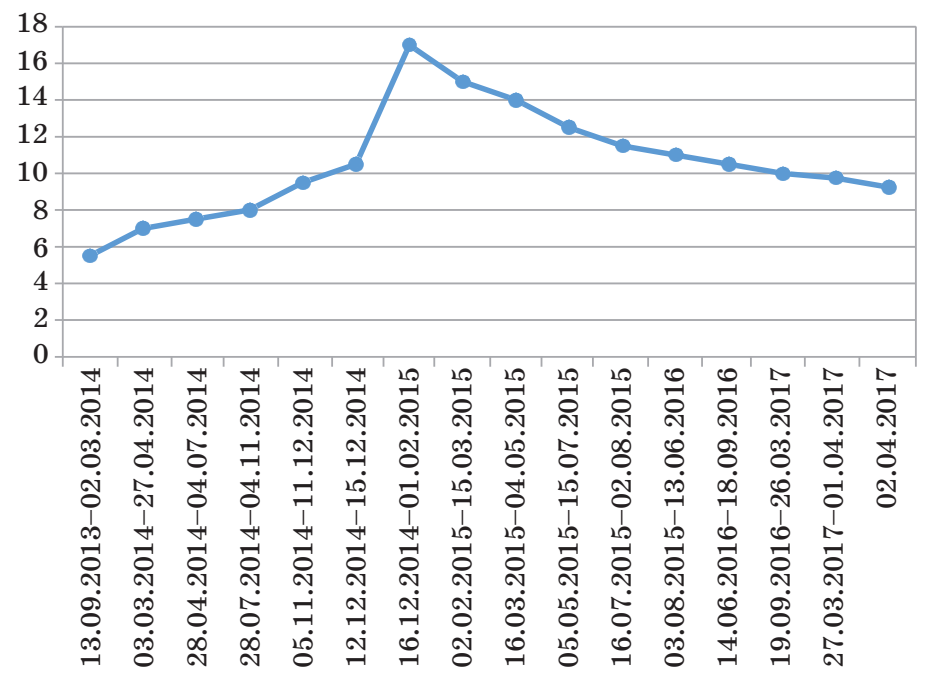

Рис. 1. Диналика ключевой ставки Банка России в 2013-2017 г2. (Составлено по данныл ЦБ РФ (http://www.cbr.ru/statistics/print.aspx) и [3])

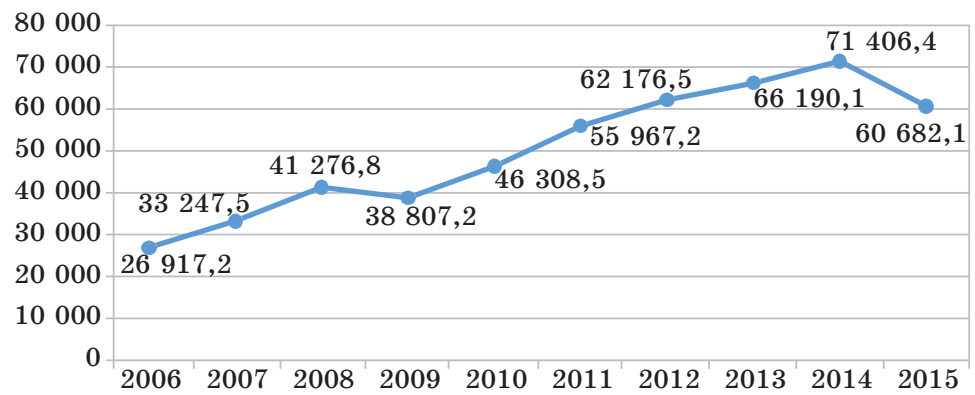

Рис. 2. Динамика ВВП в 2006-2015 г2. (на 31 декабря), млрд р.

(Составлено по данным: URL: http://quote.rbc.ru/macro/indicator/1/2/ u [3])

В рамках данной статьи считаем целесообразным рассмотреть Банк России, как контролирующий орган второго уровня банковской системы, его действия по обеспечению развития и укрепления банковской системы Росси. В связи с расширением полномочий Банком России и получения статуса мегарегулятора, расширились полномочия органа регулирования, что усилило его влияние на финансовые институты. При этом, его главной задачей, по нашему мнению, остается соблюдение одной их главных целей банковского регулирования и банковского надзора, которые в соответствии с федеральным законом являются поддержание стабильности банковской системы Российской Федерации и защита интересов вкладчиков и кредиторов ${ }^{4}$.

Исходя из определения банковской системы в законе «О банках и банковской деятельности» № 395-1-Ф3 банковская система включает в себя Банк России, кредитные организации, а также представительства иностранных банков ${ }^{5}$.

В экономической научной литературе имеет место быть большое количество толкований понятия «банковская система». В большинстве научных трудов и мо-

${ }^{4}$ О Центральном банке Российской Федерации (Банке России) : федер. закон от 10 июля 2002 г. № 86-ФЗ (в ред. от 4 нояб. 2014 г.).

${ }^{5}$ О банках и банковской деятельности : федер. закон РФ от 2 дек. 1990 г. № 395-ФЗ (ред. от 4 нояб. 2014 г.) // СПС «КонсультантПлюс».

\section{Baikal Research Journal}


нографий отдается предпочтение изучению сущности финансового посредничества, роли банков в экономике, их функциям и задачам, структуре банковской системы. Среди авторов следует выделить определение, выдвинутое О. И. Лаврушиным, который считает, что банковская система представляет собой совокупность банков, банковской инфраструктуры, банковского законодательства и банковского рынка, находящиеся в тесной взаимосвязи друг с другом и внешней средой [3]. М. А. Алленых выделяет понятие банковской системы как институт рыночной экономики [4]. Хеинсворт определяет банковскую систему как формальных и не формальных юридических прав и норм, которые упорядочивают взаимодействие экономических агентов в процессе создания дополнительной покупательной способности [5]. Так же о понятии банковской системы писали такие авторы как С. В. Коптякова [6], И. Т. Балабанов [7]. Про неограниченность банковской системы только кредитными организациями, а добавлением в исследуемое понятие другие организации и учреждения, обеспечивающие стабильное функционирование фундаментального блока системы: банков и иных кредитных организаций на основе Российской банковской энциклопедии описывал А. В. Молчанов [8].

Исходя из целей, поставленных перед Банком России в настоящий момент, рассчитывать на ускоренное развитие банковского сектора не стоит, Банк России с 2013 г. сфокусировал свое внимание на централизацией всего банковского сектора и достижения планового показателя по уровню годовой инфляции в 4 \% . По мнению аналитиков и экспертов это связано как со слабым финансовым состоянием значительного числа кредитных организаций, так и нарушение требований регулятора в части ведения банковского бизнеса. На конец 2016 г. в России зарегистрировано 635 кредитных организации (табл. 2). За период 2008-2016 гг. в Российской Федерации у кредитных организаций было отозвано 473 лицензий на осуществление банковских операций.

Динамика количества кредитных организаций

Таблица 2

в России и Федеральных округах 2008-2016 г2.

\begin{tabular}{|l|r|r|r|r|r|r|r|r|r|}
\hline Федеральный округ & \multicolumn{1}{|c|}{2008} & \multicolumn{1}{|c|}{2009} & 2010 & 2011 & 2012 & 2013 & 2014 & \multicolumn{1}{|c|}{2015} & 2016 \\
\hline Центральный & 621 & 598 & 585 & 572 & 564 & 547 & 504 & 434 & 367 \\
\hline $\begin{array}{l}\text { В том числе } \\
\text { г. Москва }\end{array}$ & 543 & 522 & 514 & 502 & 506 & 489 & 450 & 383 & 323 \\
\hline Северо-западный & 79 & 75 & 71 & 69 & 70 & 70 & 64 & 60 & 50 \\
\hline $\begin{array}{l}\text { В том числе } \\
\text { Г. Санкт-Петербург }\end{array}$ & 42 & 40 & 39 & 39 & 39 & 41 & 41 & 39 & 33 \\
\hline Южный & 115 & 113 & 47 & 45 & 46 & 46 & 41 & 37 & 34 \\
\hline Северокавказский & - & - & 57 & 56 & 50 & 43 & 28 & 22 & 17 \\
\hline Приволжский & 131 & 125 & 118 & 111 & 106 & 102 & 92 & 85 & 78 \\
\hline Уральский & 58 & 54 & 51 & 45 & 44 & 42 & 35 & 32 & 29 \\
\hline Сибирский & 68 & 62 & 56 & 54 & 53 & 51 & 44 & 41 & 37 \\
\hline Дальневосточный & 36 & 31 & 27 & 26 & 23 & 22 & 22 & 17 & 18 \\
\hline Крымский & - & - & - & - & - & - & 2 & 5 & 5 \\
\hline Всего & 1108 & 1058 & 1012 & 978 & 956 & 923 & 834 & 733 & 635 \\
\hline
\end{tabular}

Составлено по данным ЦБ РФ (http://www.cbr.ru/statistics/ ?PrtId=pdko) и [7].

Как показывает динамика отзывов лицензий, то обращает на себя внимание цикличность данных процессов. Так, с 2006 по 2008 г. наблюдается снижение количества отозванных лицензий, в 2009 г. - повышение, затем до 2011 г. снова снижение и с 2012 г. - рост. Понижение активности Банка России в сторону сокращения кредитных организаций зафиксировано каждые три года (20062008 гг., 2009-2011 гг.).

\section{Baikal Research Journal}

электронный научный журнал Байкальского государственного университета 
Действия Банка России вызывает не однозначную реакцию в научном сообществе, есть как и сторонники «очищения банковского сектора», так и противники. В пользу достаточно решительной политики регулятора говорит статистика причин отзывов лицензий, по данным Банка России рост количества кредитных организаций, по которым были приняты решения об отзыве лицензий на осуществление банковских операций, в 2014 г. объясняется, в основном, их активной вовлеченностью в отмывание доходов, полученных преступным путем и финансирования терроризма и незаконным выводом денежных средств за рубеж, потребовавшей применения жестких мер реагирования со стороны надзорного органа. При этом необходимо отметить, что большинство кредитных организаций, попавших в поле зрения регулятора, прекратили подобного рода деятельность, однако, в ряде случаев 36 кредитных организаций или $42 \%$ от количества кредитных организаций, у которых отозваны лицензии Банк России был вынужден реализовать предоставленное законом правом применить крайнюю меру воздействия.

Значительная часть отзывов лицензий стала итогом накопившихся у кредитных организаций финансовых проблем с последующей утратой капитала и (или) устойчивой неплатежеспособностью - 33 кредитные организации или 38 \% от количества кредитных организаций, у которых отозваны лицензии. При этом отдельные кредитные организации скрывали свое реальное финансовое положение, представляя в Банк России существенно недостоверную отчетность - 13 кредитных организаций или $15 \%$ от количества кредитных организаций, у которых отозваны лицензии (табл. 3).

Таблица 3

Основания для отзыва лицензии кредитных организаций в период 2007-2016 г2.

\begin{tabular}{|l|r|}
\hline \multicolumn{1}{|c|}{ Основания для отзыва лицензии } & $\begin{array}{r}\text { Количество } \\
\text { отозванных } \\
\text { лицензий }\end{array}$ \\
\hline Установление фактов существенной недостоверности отчетных данных & 80 \\
\hline Задержка более чем на 15 дней представления ежемесячной отчетности & 3 \\
\hline $\begin{array}{l}\text { Осуществление, в том числе однократное, банковских операций, не предусмо- } \\
\text { тренных лицензией }\end{array}$ & 2 \\
\hline $\begin{array}{l}\text { Неисполнение федеральных законов, регулирующих банковскую деятельность, } \\
\text { а также нормативных актов Банка России, если в течение одного года к кре- } \\
\text { дитной организации неоднократно применялись меры, предусмотренные Ф3 } \\
\text { «О Центральном банке Российской Федерации (Банке России)» }\end{array}$ & 304 \\
\hline $\begin{array}{l}\text { Неоднократное нарушение в течение одного года требований, предусмотренных } \\
\text { ст. 6 и 7 (за исключением п. 3 ст. 7) Федерального закона № 115-Ф3 }\end{array}$ & 163 \\
\hline $\begin{array}{l}\text { Неоднократное непредставление в установленный срок в Банк России обновлен- } \\
\text { ных сведений, необходимых для внесения изменений в единый государственный } \\
\text { реестр юридических лиц, за исключением сведений о полученных лицензиях }\end{array}$ & 1 \\
\hline Достаточность капитала ниже 2 \% & 53 \\
\hline $\begin{array}{l}\text { Размер собственных средств (капитала) ниже минимального значения уставно- } \\
\text { го капитала, установленного на дату государственной регистрации кредитной } \\
\text { организации }\end{array}$ & 55 \\
\hline $\begin{array}{l}\text { Неисполнение в срок требования Банка России о приведении в соответствие } \\
\text { величины уставного капитала и размера собственных средств (капитала) }\end{array}$ & 103 \\
\hline $\begin{array}{l}\text { Неисполнение в срок требования Банка России о приведении в соответствие } \\
\text { величины уставного капитала и размера собственных средств (капитала) }\end{array}$ & 1 \\
\hline $\begin{array}{l}\text { Снижение в течение трех месяцев подряд размера собственных средств } \\
\text { (капитала) ниже 180 млн р. }\end{array}$ & 2 \\
\hline $\begin{array}{l}\text { Снижение в течение трех месяцев подряд размера собственных средств (капитала) } \\
\text { ниже размера собственных средств (капитала), достигнутого на 1 января 2007 г. }\end{array}$ & 6 \\
\hline $\begin{array}{l}\text { Недостижение по состоянию на 1 января 2010 г. размера собственных } \\
\text { средств (капитала), установленного частью пятой статьи 11.2 Ф3 «О банках и } \\
\text { банковской деятельности» - 90 млн р. }\end{array}$ & \\
\hline
\end{tabular}

Составлено по данным ЦБ РФ (http://www.cbr.ru/publ/god/ar_2016.pdf).

\section{Baikal Research Journal}

электронный научный журнал Байкальского государственного университета 
В пользу сторонников критики действий ЦБ РФ говорят объективные факторы такие как:

1. Рост недоверия к банковскому сектору.

2. Потеря денежных средств юридических лиц (в связи с отсутствием их в системе страхования).

3. Агрессивная политика отталкивает иностранных инвесторов.

4. Централизация финансовых потоков в центральных регионах России.

В настоящий момент Банк России сталкивается с серьезными вызовами. Финансовый кризис, который длиться с 2007 г., а в 2014 г. произошла вторая волна, обострив проблемы в экономике и банковском секторе в частности, обострил проблемы банковской системы. По мнению коллектива авторов Высшей школы экономики: М. Мамонов, А. Пестова, О. Солнцев проблемная ситуация в банковском секторе вызвана тремя факторами:

1. Признаки нового «перегрева» кредитного рынка.

2. Формирование среди системно значимых банков обширной группы риска.

3. Обострение проблемы недобросовестного поведения фактических собственников банков ${ }^{6}[9]$.

Мегарегулятору необходимо обращать основное внимание на качество активов кредитных организаций, заинтересованность собственников в устойчивости кредитной организации, заниматься просветительской работой населения, в рамках политики роста финансовой грамотности.

Динамика изменений организационной структуры Банка России в ходе управленческой реформы в 2013-2015 г2.

\begin{tabular}{|c|r|rr|}
\hline Год & Количество Отделений/Управлений & Количество РКЦ \\
\hline 2013 & 79 & 503 \\
\hline 2015 & 8 & 362 \\
\hline
\end{tabular}

Составлено по данным http://www.cbr.ru/publ/god/ar_2015.pdf.

В данный момент сложно говорить о развитии банковского сегмента в России, по причине модернизации как самого Банка России (табл. 4), так и коммерческих банков, так как в сложившейся ситуации им необходимо приводить свою деятельность в соответствие с мировыми стандартами банковского бизнеса, в частности Базель III.

\section{Список использованной литературы}

1. Жигас М. Г. Развитие страховой защиты и финансово-экономические особенности страховой деятельности / М. Г. Жигас // Известия Иркутской государственной экономической академии (Байкальский государственный университет экономики и права). 2014. - № 4. - Режим доступа: http://brj-bguep.ru/reader/article.aspx?id=19289.

2. Звягинцева Н.А. Реформирование системы государственного регулирования рынка ценных бумаг: путь к мегарегулятору / Н. А. Звягинцева // Известия Иркутской государственной экономической академии. - 2013. - № 5 (91). - С. 27-34.

3. Лаврушин О. И. Банковская система в современной экономике : учеб. пособие / О. И. Лаврушин. - 2-е изд. - М. : КноРус, 2016. - 360 с.

4. Алленых М. А. Банковская система как институт рыночной экономики / М. А. Алленых // Банковские услуги. - 2007. - № 8. - С. 2-8.

5. Хейнсворт Р. Переход от банковского сектора к банковской системе: условия достаточные и необходимые / Р. Хейнсворт // Деньги и кредит. - 2003. - № 6. - С. 19-24.

6. Коптякова С. В. К вопросу о трактовках понятия «банковская система» / С. В. Коптякова // Известия Оренбургского государственного аграрного университета. - 2011. T. 2, № 30-1. - C. 158-161.

${ }^{6}$ Регулирование банковского сектора // Высшая школа экономики. URL: http://www.hse.ru.

\section{Baikal Research Journal}


7. Деньги и финансовые институты / под ред. И. Т. Балабанова. - СПб. : Питер, 2000. - 192 с.

8. Молчанов А. В. Коммерческие банки в современной России: теория и практика / А. В. Молчанов. - М. : Финансы и статистика, 1996. -272 с.

9. Российская банковская энциклопедия : в 2 т. / ред. О. И. Лаврушин [и др.]. 3-е изд., доп. и перераб. - СПб. : Диамант, 2007. - Т. 2. - 363 с.

\section{References}

1. Zhigas M. G. Developing insurance coverage and finance and economic features of insurance activity. Izvestiya Irkutskoi gosudarstvennoi ekonomicheskoi akademii (Baykalskii gosudarstvennyi universitet ekonomiki i prava) $=$ Bulletin of Irkutsk State Economics Academy (Baikal State University of Economics and Law), 2014, no. 4. http://brj-bguep.ru/reader/ article.aspx?id=19289. (In Russian).

2. Zvyagintseva N.A. Reforming system of governmental control of security market: on the road to the mega-regulator. Izvestiya Irkutskoi gosudarstvennoi ekonomicheskoi akademii = Bulletin of Irkutsk State Economics Academy, 2013, no. 5 (91), pp. 27-34. (In Russian).

3. Lavrushin O. I. Bankovskaya sistema v sovremennoi ekonomike [Banking system in modern economic paradigm]. $2^{\text {nd }}$ ed. Moscow, KnoRus Publ., 2016. 360 p.

4. Allenykh M. A. Banking system as an institution of market economy. Bankovskie uslugi $=$ Banking Services, 2007, no. 8, pp. 2-8. (In Russian).

5. Kheinsvort R. Transition from banking sector to banking system: sufficient and necessary terms. Den'gi $i$ kredit = Money and Credit, 2003, no. 6, pp.19-24. (In Russian).

6. Koptyakova S. V. On issue of interpreting the concept «banking system». Izvestiya Orenburgskogo gosudarstvennogo agrarnogo universiteta $=$ Bulletin of Orenburg State Agrarian University, 2011, vol. 2, no. 30-1, pp. 158-161. (In Russian).

7. Balabanov I. T. (ed.). Den'gi $i$ finansovye instituty [Money and financial institutions]. Saint Petersburg, Piter Publ., 2000. 192 p.

8. Molchanov A. V. Kommercheskie banki v sovremennoi Rossii: teoriya i praktika [Commercial banks in modern Russia: theory and practice]. Moscow, Finansy i statistika Publ., 1996. 272 p.

9. Lavrushin O. I. et al. (eds). Rossiiskaya bankovskaya entsiklopediya [Russian Banking Encyclopedia]. $3^{\text {rd }}$ ed. Saint Petersburg, Diamant Publ., 2007. Vol. 2. 363 p.

\section{Информация об авторах}

Жигас Маргарита Герутисовна - доктор экономических наук, профессор, заведующий кафедрой банковского дела и ценных бумаг, Байкальский государственный университет, 664003, г. Иркутск, ул. Ленина, 11, e-mail: GigasMG@bgu.ru.

Чекурков Геннадий Владимирович - магистрант, кафедра банковского дела и ценных бумаг, Байкальский государственный университет, 664003, г. Иркутск, ул. Ленина, 11, e-mail: Gennady.chekurkov@yandex.ru.

\section{Authors}

Margarita G. Zhigas - Doctor habil. (Economics), Professor, Head of Chair of Banking and Securities, Baikal State University, 11 Lenin St., 664003, Irkutsk, Russian Federation; e-mail: GigasMG@bgu.ru.

Gennady V. Chekurkov - Master Degree Student, Chair of Banking and Securities, Baikal State University, 11 Lenin St., 664003, Irkutsk, Russian Federation; e-mail: Gennady. chekurkov@yandex.ru.

\section{Библиографическое описание статьи}

Жигас М. Г. Роль Банка России в совершенствовании российской банковской системы / М. Г. Ж игас, Г. В. Чекурков // Baikal Research Journal. - 2017. - T. 8, № 2. - DOI: 10.17150/2411-6262.2017.8(2).6.

\section{Reference to article}

Zhigas M. G., Chekurkov G. V. Role of Russia's Central Bank in improving Russian banking system. Baikal Research Journal, 2017, vol. 8, no. 2. DOI: 10.17150/2411-6262.2017.8(2).6. (In Russian).

\section{Baikal Research Journal}

